\title{
OBSTÁCULOS PERCEBIDOS POR PAIS E PROFESSORES NO ATENDIMENTO DAS NECESSIDADES DE CRIANÇAS COM EPILEPSIA
}

\author{
Maria de Lourdes da Rocha Rosa*
}

ROSA, M.L.R. Obstáculos percebidos por pais e professores no atendimento das necessidades de crianças com epilepsia. Rev.latino-am.enfermagem, Ribeirão Preto, v. 5, número especial, p. 37-44, maio 1997.

O presente estudo relata os problemas e dificuldades percebidas por mães e professores de crianças portadoras de epilepsia, que foram atendidas na área de Neurologia, no Ambulatório Regional de Especialidades de uma cidade de porte médio do Estado de São Paulo. Teve como objetivos: 1. Caracterizar problemas e necessidades percebidas por pais e professores de crianças epilépticas em situação de crise convulsiva. 2. Caracterizar o atendimento que pais e professores vêm dando para atender as necessidades específicas de crianças epilépticas. 3. Propor alternativas que possam auxiliar mães e professores, particularmente, na situação de crise convulsiva. À amostra deste estudo constituiu-se de mães e professores de 10 crianças portadoras de epilepsia, de ambos os sexos, na faixa etária de 7 a 14 anos.

\section{UNITERMOS: criança epiléptica, crise convulsiva, enfermagem psiquiátrica}

\section{INTRODUÇÃO}

A epilepsia é considerada mais uma síndrome do que uma doença. Pode ser definida como descarga neuronal, resultando em distúrbios da função cerebral. O distúrbio pode manifestar-se na forma de perda da consciência aumento excessivo ou perda do movimento ou de tônus muscular, transtornos das sensações ou sentidos especiais, ou interferência nas funções autônomas do corpo, tais como batimentos cardíacos ou respiração. As crises têm origem em descargas excessivas das células nervosas do cérebro e são acompanhadas de perturbações súbitas nas funções orgânicas ou mentais. Se as convulsões são recorrentes, considera-se o indivíduo afetado como padecendo de epilepsia.

Apesar da epilepsia ser um distúrbio neurológico que afeta a vida da pessoa, da família e da escola, poderá também influir no relacionamento social dos portadores. Neste sentido, a introdução aborda três enfoques distintos que são:

$$
\begin{aligned}
& \text { Enfoque médico } \\
& \text { Enfoque familiar } \\
& \text { Enfoque educacional }
\end{aligned}
$$

\subsection{Enfoque médico}

A natureza subjacente da epilepsia ainda não está esclarecida, mas os cientistas em geral acreditam que há no tecido cerebral normal certa estabilidade entre os processos de excitação e inibição, e que na epilepsia o equilíbrio é perdido, predominando a excitação. A excitabilidade pode estar circunscrita a uma pequena área ou então propagar-se e comprometer todo o cérebro e a medula espinal, caso em que ocorre convulsão grave (ROBB et al., 1984, p. 1-2).

Para LEFEVRE et al. (1980, p. 619) a epilepsia sempre foi considerada doença de ocorrência muito frequente e com nítida prevalência para se manifestar em crianças. É fácil entender essa prevalência em crianças: elas têm um sistema nervoso imaturo e, portanto, estão mais sujeitas a infecções acompanhadas de hipertermia e distúrbios hidroeletrolíticos, constituindo, portanto, um grupo mais susceptível às crises epilépticas.

AJURIAGUERRA (1980, p. 532) destaca que crianças têm uma predisposição maior às crises convulsivas que os adultos, levando em conta a maturação do sistema nervoso central nessa época da vida e considerando-se também as características próprias das crises convulsivas e as manifestações as crises que variam com a idade.

\subsection{Enfoque familiar}

ROWAN \& SCOTT (1970, p.146-47) citam, como exemplos, providências que deveriam ser tomadas quando os pais notassem algum sintoma em seu filho. As medidas de ajuda seriam: colocar a criança em local onde ela não se vira; girar sua cabeça para o lado; colocar algo macio entre os dentes, para prevenir que morda a língua; enfatizar para ela que não vai acontecer nada de

* Professora Assistente do Departamento de Ciências da Saúde da UFAC-Especialista em Enfermagem Psiquiátrica e mestre em educação Especial 
grave durante a crise. Os pais de crianças epilépticas que freqüentam escola comum devem notificar os professores da condição delas, inclusive se estão sob medicação anticonvulsivante.

Para LINS (1983, p.305-7), as atitudes inadequadas da população desinformada têm sido registradas não apenas entre as pessoas estranhas ao paciente, mas também entre os próprios componentes de seu grupo familiar, e ocorrem desde a infância, quando os pais freqüentemente se tornam superprotetores, adotando atitudes restritivas à vida social da criança, proibindo-lhe a participação em atividades coletivas, entre as quais o próprio comparecimento à escola. A insegurança dos pais de pacientes epilépticos, embora na maioria das vezes se relacione com a desinformação, podem também estar vinculada ao temor de conseqüências tanto de saúde (possibilidade de uma lesão subjacente não diagnosticada, ocorrências de efeitos colaterais por uso de drogas etc...) como sociais (interesse em evitar que a sociedade se aperceba do caso e traga transtornos a criança ou à sua família).

O encobertamento por parte da família de certa forma dificulta a classe médica e aos pesquisadores conhecer o número real da freqüência de epilepsia na população geral e em particular nas crianças em idade escolar.

\subsection{Enfoque educacional}

PUPO (1971, p.161) enfatiza a necessidade de uma mudança de atitude perante o epiléptico.

Este autor nos fala da importância da divulgação ampla dos conhecimentos atuais sobre epilepsia, no sentido de criar atitudes favoráveis aos epilépticos no ambiente familiar, social, escolar e de trabalho, e ressalta a importância de incentivar o movimento educacional de professores de nível primário e secundário no sentido de divulgar os conhecimentos gerais sobre epilepsia. Por outro lado, BOSHES \& GIBBS (1976, p.143) aponta que os professores devem ser instruidos sobre crises epilépticas, no sentido de compreenderem a natureza do problema de seus alunos, encorajá-los e assistí-los durante o período de aprendizagem.

É da maior importância que o epiléptico tenha uma vida escolar normal.

Para que isso possa acontecer, é indispensável que os professores sejam esclarecidos sobre o problema, para que possam agir adequadamente. Um professor desavisado pode, em presença de uma crise, adotar atitudes desastrosas para com o estudante, não só na maneira de lidar com ele como também no modo de agir junto aos demais alunos.

Uma vez que ocorre alta incidência de epilepsia na idade escolar, aumentam as exigências de atenção e cuidados quanto ao atendimento das crianças em suas necessidades básicas de natureza física, emocional e social, como por exemplo: sono, repouso, oxigenação, atividades físicas, aprendizagem, (educação e saúde), lazer, auto-realização, auto-estima etc ...

Nas crianças afetadas pelo quadro epiléptico, aumentam as necessidades de sono, de segurança, de apoio afetivo, de apoio nos processos de aprendizagem, dentre outras.

Isto faz com que exijam atenção constante de pais ou responsáveis e professores, enfim das pessoas que mantêm contato mais próximo e duradouro com elas.

Essas necessidades básicas poderão estar afetadas em níveis de intensidades diferenciadas. Neste sentido cabe apontar no mínimo três situações: de pré-crise, de crise e pós-crise, que por sua vez, exigirão de pais e/ou responsáveis e também de professores, habilidades e informações diferenciadas para lidar com cada situação.

A ausência de literatura que aborde a família e a escola da criança portadora de epilepsia no tocante às suas necessidades, a inexistência de trabalhos voltados para essa perspectiva e a falta de informações para a prestação de assistência adequada levam a família a buscar atendimento médico e/ou adotar outros procedimentos por ela considerados pertinentes.

Neste sentido, na tentativa de propor alternativa que contribuam para a superação das necessidades das crianças epilépticas que freqüentam escola comum e/ou especial, quanto para a redução das necessidades que pais e professores vêm encontrando para lidarem adequadamente com o quadro da epilepsia, com o presente trabalho, pretendeu-se alcançar os seguintes objetivos:

1. Caracterizar problemas e necessidades percebidas por pais e professores de crianças epilépticas em situação de crises convulsivas.

2.Caracterizar o atendimento que pais e professores vêem dando para atender as necessidades especificas de crianças epilépticas.

3.Propor alternativas que possam auxiliar pais e professores no atendimento das necessidades de crianças epilépticas, particularmente, na situação de crise convulsiva.

\section{METODOLOGIA}

\subsection{População}

No decorrer do mês de fevereiro de 1991, foi realizado um levantamento da população infantil atendida no período de fevereiro a março de 1990, na área de neurologia, no Ambulatório Regional de Especialidades de um Centro de Saúde de uma cidade de porte médio do Estado de São Paulo. 
Tinham recebido atendimento, no referido período, 427 crianças. Foram separadas as fichas daquelas diagnosticadas com epilepsia e que estivessem na faixa etária de 7 a 14 anos de idade, por ser uma população em idade escolar. Eram 48 crianças.

A amostra deste estudo constituiu-se de mães e professores de 10 crianças portadoras de epilepsia, de ambos os sexos, na faixa etária de 7 a 14 anos de idade, selecionadas entre aquelas que atendiam os seguintes critérios:

a.deveriam estar matriculadas e freqüentando escola comum ou especial;

b.deveriam residir no município em estudo;

c.deveriam estar sendo tratadas e com seguimento no referido ambulatório de especialidades.

\subsection{Situação da coleta de dados}

O Primeiro contato com as mães deu-se no ambulatório do Centro de Saúde, mais especificamente no corredor que dá acesso ao consultório médico, onde os clientes aguardam atendimento. Posteriormente todos os contatos foram mantidos no domicílio, através de visitas da pesquisadora para a obtenção de dados familiares.

As entrevistas com os professores foram realizadas em visitas nas escolas onde as crianças estudavam.

\subsection{Instrumentos da coleta de dados}

Decidimos adotar a entrevista como meio para a coleta de dados com as mães e professores, por ser reconhecidamente um instrumento eficaz enquanto técnica de pesquisa, e se adequava aos propósitos do presente estudo.

Para o levantamento dos dados, com as mães e professores foram elaboradas duas entrevistas com perguntas abertas e outras fechadas.

A entrevista direcionada a mães, foi composta de 15 perguntas obedecendo a seguinte sequiência:

-dados de identificação da criança;

-histórico da vida pregressa;

-conhecimentos da família sobre o "problema";

-as necessidades a serem atendidas;

-as sugestões e opiniões da família para a superação dos problemas e/ou dificuldades apontadas.

A entrevista dos professores foi constituída de 12 perguntas, que obedeceu a seguinte trajetória:

-dados de identificação da criança; -conhecimentos da professora sobre o "problema"; -a visão da professora acerca da aprendizagem; -as necessidades a serem atendidas; -saber as sugestões e opiniões da professora para a superação dos problemas e/ou das dificuldades apontadas.

\subsection{Coleta de dados}

Os dados foram coletamos pela própria pesquisadora após o primeiro contato mantido com a mãe da criança no ambulatório de neurologia.

No primeiro encontro, individual, a mãe era informada sobre os sobre os objetivos da pesquisa e era, então, convidada a participar de uma entrevista individual no seu próprio lar.

Uma vez aceito o convite, de comum acordo, marcávamos o dia e horário para realização da mesma.

Cada entrevista foi realizada conforme o dia estipulado, com exceção de uma, porque a mãe recusou ser entrevistada por questões de natureza conjugal e religiosa. Neste caso, optou-se por urna outra criança e, por conseguinte, uma nova mãe.

A entrevista com os professores efetuou-se da seguinte maneira:

1. a mãe fornecia as informações necessárias para o primeiro contato com a escola onde a criança estava matriculada;

2. entrávamos em contato com a diretoria da instituição de ensino e esclarecíamos nossa intenção de pesquisa. Um elemento da direção se encarregava de manter contato com a professora responsável pela criança e marcar o primeiro encontro, conforme os horários de atividades do professor e

3. conforme dia e horário estabelecidos e a aceitação por parte da professora, efetuávamos a entrevista em um local que nos fôra colocado à disposição.

Desta forma, todas as entrevistas foram realizadas na própria instituição de ensino e/ou de trabalho da professora.

\subsection{Análise dos dados}

As informações fornecidas pelos participantes durante as entrevistas foram anotadas durante a sua execução, conforme permissão dos mesmos.

Vale ressaltar que, por se tratar de uma pesquisa que procurou identificar e caracterizar os problemas e necessidades de crianças epilépticas, utilizamos a análise de conteúdo elegendo alguns depoimentos.

A partir de leituras e reflexões sobre análise de conteúdo e sobre os objetivos propostos na pesquisa, conseguimos sistematizar e analisar os dados pertinentes aos resultados dos depoimentos das mães e professores, o que contribuiu para uma maior clarificação das necessidades apresentadas durante as entrevistas com os mesmos.

\section{RESULTADOS E DISCUSSÃO}

Por se tratar de um estudo que percorreu momentos diversificados, é importante distingui-los: 
1. Adotamos, como primeira etapa, a análise e discussão dos dados das entrevistas com mães, e

2. Numa segunda etapa, foram analisados e discutidos os dados das entrevistas com os professores.

\subsection{Dados obtidos nas entrevistas com as mães}

Nesta primeira etapa, o trabalho revelou, dentro da estrutura familiar, a existência de necessidade de lidar com as situações de crise convulsiva na criança.

\subsection{Dados obtidos nas entrevistas com os professores}

Procuramos, nesta fase do trabalho colher informações junto aos professores sobre os problemas e dificuldades que essas crianças encontram no ambiente escolar e, ao mesmo tempo, levantar necessidades sentidas pelos respectivos professores para lidarem com crise epiléptica.

O presente levantamento permitiu indentificar inúmeras necessidades sentidas por mães e professores quando precisam lidar com situações de crises convulsivas. Contudo, elas apresentam grande diversidade: vão desde conhecimentos elementares até a solicitação de informações sobre habilidades para a aplicação de procedimentos complexos.

Desta maneira, procuramos reunir as necessidades e/ou obstáculos levantados pelas mães e professores conforme descritas a seguir:

\section{Obstáculos levantados por mães e professores de crianças portadoras de epilepsia, quando precisam lidar com situações de crises convulsivas:}

\section{MÃES}

- Demonstram despreparo para prestar assistência;

- Adotam procedimentos ineficazes para socorrer ao aluno

- Ficam perturbados emocionalmente quando surpreendidas

por crises convulsivas;

- Apresentam instabilidade emocional quando surpreendidas por uma crise convulsiva;

- Convivem com a resistências da criança em realizar as

tarefas escolares;

- Encontram dificuldades de auxiliar a criança nas tarefas - Encontram dificuldades para acompanhar o estudante escolares, por falta de informações pertinentes ao assunto; no processo ensino-aprendizagem, por falta de informações dos familiares;

- Anseiam por transferir as responsabilidades pela saúde - Anseiam por transferir as responsabilidades pela saúde da criança portadora de epilepsia a outros profissionais; da criança portadora de epilepsia a outros profissionais;

- Reclamam falta de cursos de primeiros socorros - Reclamam falta de cursos de primeiros socorros especialmente voltados para o atendimento de epilepsia; especilamente voltados para o atendimento de epilepsia:

- Indicam a falta de orientação e apoio por parte dos - Indicam a falta de orientação e apoio por parte dos profissionais da área de saúde;

- Solicitam cursos e/ou noções de primeiros socorros
voltados para o atendimento das crianças portadoras de epilepsia.

Com base nos dados analizados, foi possível discriminar as necessidades dos estudantes.

- Falta de atendimento adequado por parte de seus professores;

- Retardamento da assistência dispensada a criança durante as crises, uma vez que os professores buscam auxilio de colegas, de pessoas que passam no local e profissionais da área de saúde;

- Reconhecem a falta de acesso as informações relacionadas a saúde, e até mesmo aos locais para onde encaminhar o aluno quando apresenta uma crise convulsiva; - Revelam qua são desinformados a respeito do estado de saúde do aluno, por falta de intercâmbio entre a família e a escola, e, por isso, o aluno deixa de ser observado com mais frequência;

- Solicitam cursos de primeiros socorros e/ou treinamentos voltados para o atendimento das crianças portadoras de epilepsia.

profissionais de saúde, enquanto a criança aguarda auxilio, estando sujeita a sérias complicações no quadro clínico;

- Busca de segurança, compreensão e apoio, cuja falta os leva ao isolamento e a solidão;

- Manifestação de várias formas de agressividades, que comprometem o relacionamento; 
- Necessidade de serem vistos sem discriminação;

- Necessidade de maior atenção por parte dos professores, com relação as disciplinas que não conseguem dominar; - Manifestação de lentidão do pensamento que os impede de assimilar melhor;

- Prejuízo da visão e na fala;

- Inquietação;

- Necessidade do uso da terapia anticonvulsivante.

Comparando as necessidades de professores e mães, notamos que, na sua maioria, são semelhantes. Algumas daquelas consideradas distintas merecem destaque, como, por exemplo: Os professores reconhecem a falta de acesso às informações relacionadas à saúde da criança e até mesmo sobre para onde encaminhar o aluno quando ele apresentar uma crise convulsiva sem recuperação imediata; bem como revelam medo quando surpreendidos pelas crises convulsivas.

Como as dificuldades enfrentadas pelos professores foram basicamente aquelas experienciadas durante o episódio convulsivo, já relatadas anteriormente, e como carecem de informações relacionadas à assistência, deixam de proceder com sucesso, mostrandose inseguros e incapazes de controlar as próprias emoções. Estes mesmos aspectos foram identificados nas necessidades das mães, o que significa que ambos são desprovidos de conhecimentos para assistir adequadamente a criança.

\subsection{Discussão Geral}

A partir dos depoimentos obtidos pode-se depreender que nenhuma família, ao procurar assistência no sistema de saúde local, recebeu informações para resolver os problemas e atender as necessidades de seus filhos epilépticos.

Vale dizer que a clientela não está sendo contemplada pelo atendimento total, que considera as necessidades físicas, emocionais e sociais da pessoa em conseqüências da patologia.

$\mathrm{Na}$ verdade, os pais estão praticamente isolados do sistema de saúde e assim, continuam procurando atendimento, na maioria das vezes, seguindo o conselho do médico que assiste a criança: "Retornar quando a medicação estiver acabando". Em outras ocasiões a mãe retorna por conta da ausência de resposta satisfatória ao regime de tratamento escolhido, ou mesmo pela intensidade e freqüência das convulsões.

Por outro lado, os pais, além de não receberem orientação sobre o problema, sobre a terapêutica e condução dos seus filhos nas dificuldades de aprendizagem além de não conhecerem as possíveis reações da medicação, ainda deparam com o preconceito e tabús.
No entanto, desprotegidos de informações, procuram, de certa forma, se adaptarem às situações, superprotegendo os filhos, impossibilitados de participarem de tudo o que seria ideal para uma criança na idade escolar.

Talvez o aspecto mais importante da administração de crises convulsivas para os médicos seria uma discussão com os pais e a própria criança, sobre a indisposição e, independentemente do regime de tratamento escolhido, uma supervisão cuidadosa da criança em intervalos regulares e apropriados. Estes podem ser semanais, mensais ou semestrais, dependendo da severidade e frequiência das crises convulsivas.

Ambas as partes (pais e crianças) devem entender porque está sendo dada a medicação e estarem atentas aos riscos reais do esquecimento do uso da mesma.

Eles devem ser ajudados a rejeitar os mitos associados à epilepsia, evitar a superproteção e perceber a necessidade da criança levar uma vida normal.

Acreditamos que aproximadamente quinze minutos de conversação que o médico gaste para explicar o diagnóstico, a medicação de que deve fazer uso servem para facilitar o relacionamento e abrir caminhos para a cooperação e entendimento. Conseqüentemente, o problema do medo, a insegurança e superproteção por parte da família diminuirão.

Quanto aos professores, estão intervindo sem receber qualquer tipo de orientação de profissionais de saúde, ou seja, de médicos e enfermeiros, que fazem parte do sistema de saúde. Eles se defrontam com a síndrome e buscam meios no própria ambiente com vistas a atender situações de crise.

A falta de colaboração da família em informar a escola sobre o problema da criança dificulta o atendimento, contribuindo para a não aproximação. Julgamos que esse procedimento familiar facilita a manutenção do espaço da mesma na escola. Ela encobre o problema talvez para ver a criança caminhando na escola igual aos irmãos, por medo da discriminação e de prováveis prejuízos que ele pode acarretar na aprendizagem e na sociabilização. Assim, o encobertamento da família pode ser um esforço de certa forma positivo para reduzir o estigma enfrentado pelo sujeito epiléptico e por ela própria.

$\mathrm{Na}$ maioria das vezes, quando acontece uma convulsão em sala de aula ou em outra dependência escolar, a criança passa a ser alvo de comentários, dos olhares dos colegas, dos professores e de outros possíveis presentes.

Acredita-se que as razões para isso são múltiplas e complexas.

Entretanto, um fator significativo é a supertição do povo, compreensível entre os professores, colegas de classe e outras pessoas.

Segundo Stefanelli 1977 apud CARDOSO, 
(1992, p.4), "os preconceitos constituem forte barreira na aceitação da pessoa como ser humano, e por causa deles, o próprio epiléptico expressa medo de sua condição".

$\mathrm{Na}$ mesma linha de pensamento, CARDOSO (1992, p. 5) assegura que, quando os tabús e conceitos místicos forem totalmente erradicados será possível fornecer o tratamento no sentido mais amplo para os epilépticos.

$\mathrm{O}$ acesso às informações e condutas adequadas resultarão em mudanças.

$\mathrm{O}$ envolvimento dos professores, familiares e crianças nos obstáculos citados no decorrer do trabalho, provavelmente, provoca uma tendência a mudança.

Não mudança imediata, mas a longo prazo, uma vez que os estigmas associados à epilepsia remontam há milhares de anos.

Em razão disso, espera-se que o sistema de saúde trabalhe na tentativa de procurar solucionar os problemas e necessidades dos familiares, dos professores e das crianças, aproveitando os serviços já existentes e em alguns casos, criando outras condições de atendimento.

A partir dessas informações, pode-se perceber que os dados sugerem a proposta de um programa de atendimento direcionado aos pais em beneficio da clientela portadora de epilepsia, na idade escolar, que busca atendimento médico especializado no Centro de Saúde.

$\mathrm{O}$ atendimento que vem sendo realizado para essa população seria de maior eficácia se incluísse professores das crianças, quer da escola comum quer da especial.

Os dados também sugerem:

- treinamento para os profissionais da área de saúde, com finalidade de atualizar seus conhecimentos sobre epilepsia, para poderem oferecer atendimento aos pais.

- no curso de formação para Professores de $1^{\circ}$ grau dar ênfase em primeiros socorros para que os professores tornem-se capazes intervir em situações reais,

- elaboração de folhetos informativos sobre epilepsia com destaque para a assistência.

Para tanto, pode-se oferecer como subsídios às mães e professores de crianças epilépticas o que segue: - caracterizar a epilepsia segundo sua causa, sinais, íntercorrência, formas de assistência, tratamento e estigmas associados;

- identificar sinais na situação de pré-crise convulsiva;

- prestar assistência de urgência durante e após a crise convulsiva;

- utilizar recursos disponíveis no ambiente para facilitar a assistência;

- treinar habilidades que permitem a aplicação de procedimentos de forma correta e segura;

- fazer encaminhamentos para unidades de saúde após a crise convulsiva;
- discriminar as instituições de saúde que prestam atendimento em situações de crises convulsivas daquelas que fazem acompanhamento do estado de saúde de crianças epilépticas;

- identificar meios para a criança realizar as tarefas escolares no domicílio de forma eficiente;

- proporcionar atividades que permitam a interação da criança epiléptica com as demais da mesma faixa etária e do mesmo período escolar e

- ensinar a professora como buscar informações sobre programas de saúde propostos para o atendimento dos portadores de epilepsia.

Acreditamos que, se os familiares e professores forem instruidos para mudarem de atitudes, recebendo informações pertinentes às crises convulsivas em crianças, buscando alternativas que favoreçam o bem-estar delas e, sobretudo, adquirindo condições para participarem do ensino-aprendizagem dessas crianças poderão contribuir sobremaneira para o desenvolvimento e ajustamento da criança epiléptica com menos angústia e com mais conhecimento.

\section{COMENTÁRIOS FINAIS}

O presente trabalho relata o resultado de um levantamento onde se procurou indentificar as necessidades de mães e professores em lidar com situações de crise convulsiva em crianças portadoras de epilepsia, que freqüentam escolas comum e/ou especial.

Percebemos a relevância de várias necessidades identificadas. Entre elas, a que mais nos chamou a atenção diz respeito à assistência oferecida à criança. Vale salientar que as necessidades foram emitidas pelas mães e professores e serão descritas a seguir: utilizam recursos caseiros com o intuito de minorar os sintomas gerados por ocasião da crise convulsiva e por falta de esclarecimentos pertinentes a patologia, buscam atendimento médico por insegurança e desconhecimentos de procedimentos adequados e como recurso imediato a busca de segurança emocional ou por reconhecerem que as condutas que adotam são ineficentes; utilizam-se de suas emoções e sentimentos como forma de suportar as situações adversas relacionadas à epilepsia; apresentam labilidade emocional comprometida quando surpreendidos por uma crise convulsiva e demonstram desejo de transferência de responsabilidade pela saúde da criança quando mencionam outros profissionais para assumirem a saúde da criança.

Ficou evidente que os pais e professores foram da mesma opinião em solicitar cursos e/ou noções de primeiros socorros por reconhecerem as limitações de conhecimentos. E quando um número bastante significativo diz "desejo saber tudo sobre epilepsia", 
demonstra a amplitude dessas limitações. Também foi detectada, entre o grupo de mães, a necessidade de conhecimentos relacionados a crendices populares. Isto explica a falta de informações, o que as conduz buscar outras alternativas de assistência até mesmo daquelas voltadas para a superstição.

Quanto à aprendizagem, ficou claro, pelas informações das mães e professores que as crianças apresentam dificuldades parciais e/ou totais, essas dificuldades estiveram presentes com maior freqüências nas crianças que fazem parte do ensino especial.

Só foi constatado sucesso em um aluno. Ainda quanto à aprendizagem, um outro aspecto que nos parece pertinente: a dificuldade das mães em acompãnhar a evolução escolar dos filhos parece resultar de sua própria insuficiência de conhecimentos. Também por isso convivem com a resistência deles em realizar as tarefas escolares porque não as compreendem bem.

A falta de comunicação foi outro aspecto identificado nas escolas estudadas. Não foi detectado nenhum meio de informação entre familiares e professores que permitissem registro sobre o estado de saúde da criança.

Outro aspecto a considerar no presente trabalho, é o índice de crianças que encontram dificuldades no aprendizado escolar. Alguns professores tentaram esclarecer-nos que um número significativo das crianças do ensino especial apresenta uma certa lentidão de pensamento e, muitas vezes, requer um pouco mais de tempo para emitir respostas adequada ao que foi perguntado. Talvez a reação esteja relacionada com o tipo de crises convulsivas que a criança apresenta, com a terapia com drogas antiepilépticas e os possíveis efeitos colaterais advindos do seu uso.

Um outro aspecto identificado foi a presença de desvios comportamentais em algumas crianças, tais como: tensão nervosa, agressividade, agitação, isolamento e relacionamento social insatisfatório.

No entanto, não podemos afirmar que tais desvios sejam provenientes das crises convulsivas e/ou dos medicamentos antiepilépticos. Nossa dúvida resulta do fato de pouco se conhecer sobre os efeitos especificos dos medicamentos na aprendizagem e no comportamento de crianças na idade escolar. Também os dados existentes em nossa trabalho não são suficiente para uma conclusão sobre a dificuldade de aprendizagem. Assim, não podemos inferir que a epilepsia determina estes comportamentos na criança.

A realização deste trabalho nos levou à descoberta de inúmeras necessidades, que até então, pouco haviam sido exploradas.

O propósito de nossa pesquisa foi atingido a partir de quando os pais e professores compreenderam suas limitações e expressaram interesse em adquirir conhecimentos que lhes possibilitassem lidar com os aspectos mais complexos das crises convulsivas.

Acreditamos que ninguém melhor do que os professores e a família para falar de suas necessidades. Por isso, forneceram-nos informações valiosas para refletirmos sobre a qualidade da assistência que vem sendo dispensada à criança portadora de epilepsia.

Com base nos comentários elaborados pelos próprios professores, vimos que as necessidades dos mesmos são inúmeras, como também as de seus alunos.

Concluímos que os resultados sugerem a proposta de um programa de atendimento para pais e professores de crianças com epilepsia visando a capacitação para o atendimento de necessidades dessas crianças.

\section{OBSTACLES PERCEIVED BY PARENTS AND TEACHERS IN THE CARE OF EPILEPTIC CHILDREN}

This study reports the problerms and difficulties perceived by parents and teachers of epileptic children, who have been attended in the Neurological ward of a hospital located in a medium - size cite of the state of São Paulo, Brazil. The goals of this work are: 1. To characterize problems and needs detected by parents and teachers of epileptic children under convulsive crises. 2. To caracterize the assistance that parents and teachers have been giving in order to meet the specific needs of epileptic children. 3. To propose alternatives that can help mothers and teachers, particularly in the situation of convulsive crises. The sample of this study was formed by mothers and teachers of 10 epileptic children, male or female from 7 to 14 years old.

KEY WORDS: epileptic children, convulsive crises, psychiatric nursing

\section{OBSTÁCULOS PERCIBIDOS POR PADRES Y PROFESORES EN LA ATENCIÓN DE LAS NECESIDADES DE LOS NIÑOS CON EPILEPSIA}

El presente estudio relata los problemas y dificultades percibidos por madres y profesores de niños portadores de epilepsia que fueron atendidas en el área de neurología en un Centro Regional de Especialidades, en una ciudad de porte medio del Estado de São Paulo. Tuvo como objetivos: 1 - Caracterizar problemas y necessidades percibidas por padres y profesores de 
niños en situación de crisis convulsiva. 2 - Caracterizar la atención que padres y profesores vienen dando para atender necesidades específicas de niños epilépticos. 3 - Proponer alternativas que puedan auxiliar a las madres y profesores, particularmente en situación de crisis convulsiva. La muestra de este estudio fue formado por madres y profesores de 10 niños portadores de epilepsia de ambos sexos y en la faja etarea de 7 a 14 años.

TÉRMINOS CLAVES: niño epiléptico, crisis convulsiva, enfermería psiquiátrica

\section{REFERÊNCIAS BIBLIOGRÁFICAS}

01. AJURIAGUERRA, J. Manual de psiquiatria infantil.2 ed. São Paulo: Vozes, 1980. p.532-51.

02. BOSHES, L. D.; GIBBS, F. Manual de epilepsia. São Paulo: Manole, 1976. p.143.

03. CARDOSO, E. E. O estigma do epiléptico e a assistência de enfermagem. In: CONGRESSO BRASILEIRO DE ENFERMAGEM, 44, Brasília-DF: Associação Brasileira de Enfermagem, 1992. p.4-5.

04. LEFÈVRE, A.B. et al. Neurologia infantil: simiologia + clínica + tratamento. São Paulo: Sarvier, 1980. p.629.
05. LINS, S.G. Epilepsia. Recife: Edição Universitária, 1983. p.305-7.

06. PUPO, P.P. Questões sobre epilepsia. 2. ed. São Paulo, 1971. p. 161.

07. ROBB, P. et al. Epilepsia: manual para trabalhadores de saúde. Washington: Organização PanAmericana de Saúde, 1984. p.19 (Publicação Cientifica, 447).

08.ROWAN, A.J.; SCOTT, D. The management children with epilepsy. Practtioner, v.204, p.136-48, 1970. 